\title{
Tunica Vaginalis Thickening, Hemorrhagic Infiltration and Inflammatory Changes in 8 Children with Primary Hydrocele; Reactive Mesothelial Hyperplasia? A Prospective Clinical Study
}

\author{
Ioannis Patoulias ${ }^{1}$, Evangelia Rachmani ${ }^{1}$, Maria Kalogirou², Kyriakos Chatzopoulos ${ }^{3}$, \\ Dimitrios Patoulias ${ }^{4, *}$
}

\section{ABSTRACT}

The aim of this study is to describe an entity of primary hydrocele accompanied with fibrosis, thickening and hemorrhagic infiltration of parietal layer of tunica vaginalis (PLTV).

During a 4-year period (2011-2014), 94 boys (2.5-14 years old) underwent primary hydrocele repair. Hydrocele was right sided in 55 (58.5\%), left sided in $26(28.7 \%)$ and bilateral in 12 patients (13.8\%). Eighty three out of 94 patients (88.30\%) had communicating hydrocele and the rest eleven patients (11.7\%) had non-communicating. Our case group consists of 8 patients (8.51\%) based on operative findings consistent with PLTV induration, thickening and hemorrhagic infiltration. Preoperative ultrasonography did not reveal any pathology of the intrascrotal structures besides hydrocele. There weren't hyperechoic reflections or septa within the fluid. Evaluation of thickness of the PLTV was not feasible. Presence of lymph or exudate was excluded after fluid biochemical analysis. Tunica vaginalis histological examination confirmed thickening, hemorrhagic infiltration and inflammation, while there was absence of mesothelial cells. Immunochemistry for desmin was positive, excluding malignant mesothelioma.

One patient underwent high ligation of the patent processus vaginalis and PLTV sheath fenestration, but one year later, he faced a recurrence. An elective second surgery was conducted via scrotal incision and Jaboulay operation was performed. The latter methodology was our treatment choice in other 7 out of 8 patients. During a 2-year postoperative follow-up, no other patient had any recurrence. We conclude that in primary hydrocele with macroscopic features indicative of tunica vaginalis inflammation, reversion of the tunica should be a part of operative strategy instead of sheath fenestration, in order to minimize the recurrence.

\section{KEYWORDS}

hydrocele; boy; tunica vaginalis; inflammation; thickening; fibrosis; hemorrhagic infiltration; Lord Technique

\section{AUTHOR AFFILIATIONS}

${ }^{1} 1$ st Department of Pediatric Surgery, Aristotle University of Thessaloniki, General Hospital "G. Gennimatas", Thessaloniki, Greece

2 4th Department of Internal Medicine, Aristotle University of Thessaloniki, Hippokration General Hospital, Greece

${ }^{3}$ Department of Pathology, General Hospital "G. Gennimatas", Thessaloniki, Greece

${ }^{4}$ Department of Internal Medicine, General Hospital of Veria, Veria, Greece

* Corresponding author: M. Alexandrou 3B, Peuka, Thessaloniki, 57010, Greece; e-mail: dipatoulias@gmail.com

Received: 28 June 2017

Accepted: 5 June 2018

Published online: 14 September 2018

Acta Medica (Hradec Králové) 2018; 61(2): 41-46

https://doi.org/10.14712/18059694.2018.49

(c) 2018 The Authors. This is an open-access article distributed under the terms of the Creative Commons Attribution License (http://creativecommons.org/licenses/by/4.0), which permits unrestricted use, distribution, and reproduction in any medium, provided the original author and source are credited. 


\section{INTRODUCTION}

Hydrocele in childhood is divided into primary and secondary, based upon pathophysiology. Primary hydrocele is further divided into neonatal or congenital, communicating and closed or adult type or non-communicating (1).

Secondary hydrocele can develop due to inflammatory disorders (epididymitis, epididymo-orchitis), torsion of the testicle or embryonic tissue, inguinal hernia repair or varicocelectomy, hypoproteinemia in a systemic disease, traumatic disorders or tumours of intrascrotal structures. In the developing countries, parasitosis (lymphatic filariasis, Wuchereria bancrofti, scrotal schistosomiasis, etc.) usually causes secondary hydrocele (2).

We treated 8 patients with primary hydrocele in which fibrosis, thickening and hemorrhagic infiltration of parietal tunica vaginalis of the testicle were present. Thus, through this prospective clinical study, we aim at presenting the characteristic features of this "unknown" entity affecting tunica vaginalis, in order to facilitate the early recognition and the appropriate therapeutic approach of those patients.

\section{MATERIALS AND METHODS}

Over a 4-year period (2011-2014), 94 boys underwent hydrocele repair, due to primary hydrocele. The patients' ages ranged from 2.5 years to 14 years (mean 3.6 years). Primary hydrocele was right sided in 55 patients (58.5\%), left sided in 26 patients $(28.7 \%)$ and bilateral in 12 patients (13.8\%). Two incidents of secondary hydrocele were excluded.

Diagnosis of hydrocele is clinical and can be confirmed by ultrasonography. It is essential to clarify the onset of the scrotal swelling, while taking medical history from the parents, in order to confirm any fluctuation in size, which is an indication of primary (communicating) hydrocele.

During physical examination, we assessed the position, the turgidity and the size of the testicles, the silk-glove (or string) sign, the presence of tenderness or pain during palpation and the presence of palpable nodules on the scrotal wall or intrascrotal structures. Transillumination is also an additional method of clinical examination that should be performed if sonography is not available.

Performance of scrotal ultrasonography (US) facilitates the detection of position, size and structure of testi- cles and epididymis, the determination of echotexture of fluid and the evaluation of the presence of septa within the tunica vaginalis cavity and the diameter of processus vaginalis at the level of the internal inguinal ring.

After the performance of the typical preoperative tests, all the patients underwent elective surgery under general endotracheal anesthesia. Eighty three patients (88.3\%) had communicating hydrocele, while 11 (11.70\%) had non-communicating. After dissection of the anterior surface of tunica vaginalis, induration, thickening and hemorrhagic infiltration of it were the main macroscopic features in 8 patients. These intraoperative findings were in fact the determinants of our study subgroup.

\section{RESULTS}

Clinical and imaging findings of the 8 patients are presented in the tables 1 and 2 respectively. Classification of the patients was made based upon their age, in an ascending order (tables 1-3).

Ultrasonographic examination did not reveal any pre-existing or concomitant pathology of the intrascrotal structures, while there were no hyperechoic reflections or septa within the hydrocele fluid. Evaluation of the thickness of the parietal layer of tunica vaginalis was not feasible.

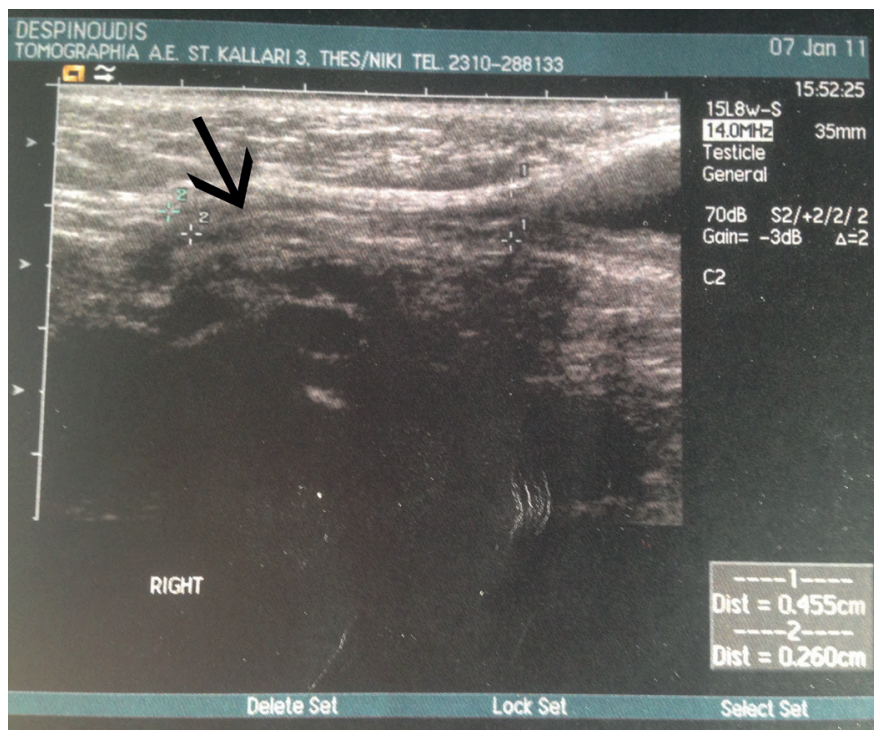

Fig. 1 Diameter of PV $(2.6 \mathrm{~mm})$ at the level of the internal inguinal ring in the 4th patient of our study group (black arrow).

Tab. 1 Clinical findings in the study group.

\begin{tabular}{|c|l|l|l|l|l|}
\hline S/n & Onset of the scrotal swelling & Fluctuation in size detected from parents & Silk sign glove & Transillumination & Co-morbidity \\
\hline 1 & From birth & Fluctuating & Yes & Ambiguous & No \\
\hline 2 & From birth & Fluctuating & Yes & Ambiguous & No \\
\hline 3 & From birth & Fluctuating & Yes & Ambiguous & No \\
\hline 4 & From birth & Stable & Yes & No & No \\
\hline 5 & From birth & Stable & Yes & No & No \\
\hline 6 & From 7 years & Increasing & No & No & No \\
\hline 7 & From 11 years & Increasing & No & No & No \\
\hline 8 & From 9 years & Increasing & No & No & No \\
\hline
\end{tabular}


Tab. 2 Range of processus vaginalis (PV) at the level of the internal inguinal ring in the study group at ultrasonographic evaluation.

\begin{tabular}{|l|l|}
\hline $\mathbf{S} / \mathbf{n}$ & $\begin{array}{l}\text { Diameter of processus vaginalis at the level of the } \\
\text { internal inguinal ring }(\mathbf{m m})\end{array}$ \\
\hline 1 & 3.1 \\
\hline 2 & 4 \\
\hline 3 & 3.6 \\
\hline 4 & 2.6 \\
\hline 5 & 4 \\
\hline 6 & Closed \\
\hline 7 & Closed \\
\hline 8 & Closed \\
\hline
\end{tabular}

The first patient detected (5th patient in tables 1, 2, 3) underwent high ligation of the processus vaginalis with'window' creation (sheath fenestration technique). Once the hydrocele was repaired, recurrence occurred within the following months and a second surgery was performed via scrotal incision and PLTV was reversed (Jaboulay technique) (Figure 2).

The rest 7 patients were treated with reversion and without excision of tunica vaginalis (Jaboulay technique, table 3, figures 3-4).

We also took tissue biopsy from the tunica vaginalis for histopathological evaluation and we collected fluid for biochemical and cytopathological examination. Presence of lymph or exudate was excluded by biochemical analysis.

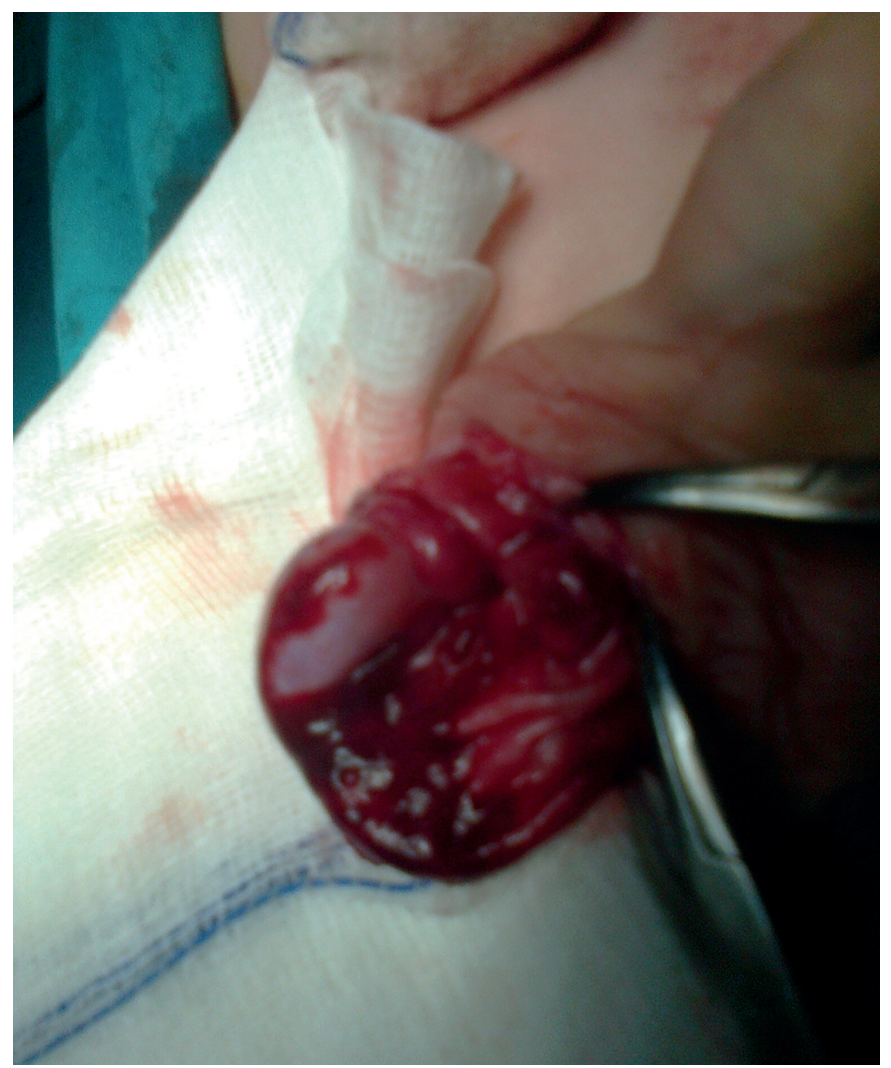

Fig. 2 After opening of the anterior surface of tunica vaginalis, via scrotal incision (5th patient of tables $1,2,3$ ), thickening and hemorrhagic infiltration of the parietal layer of tunica vaginalis were found (second operation).

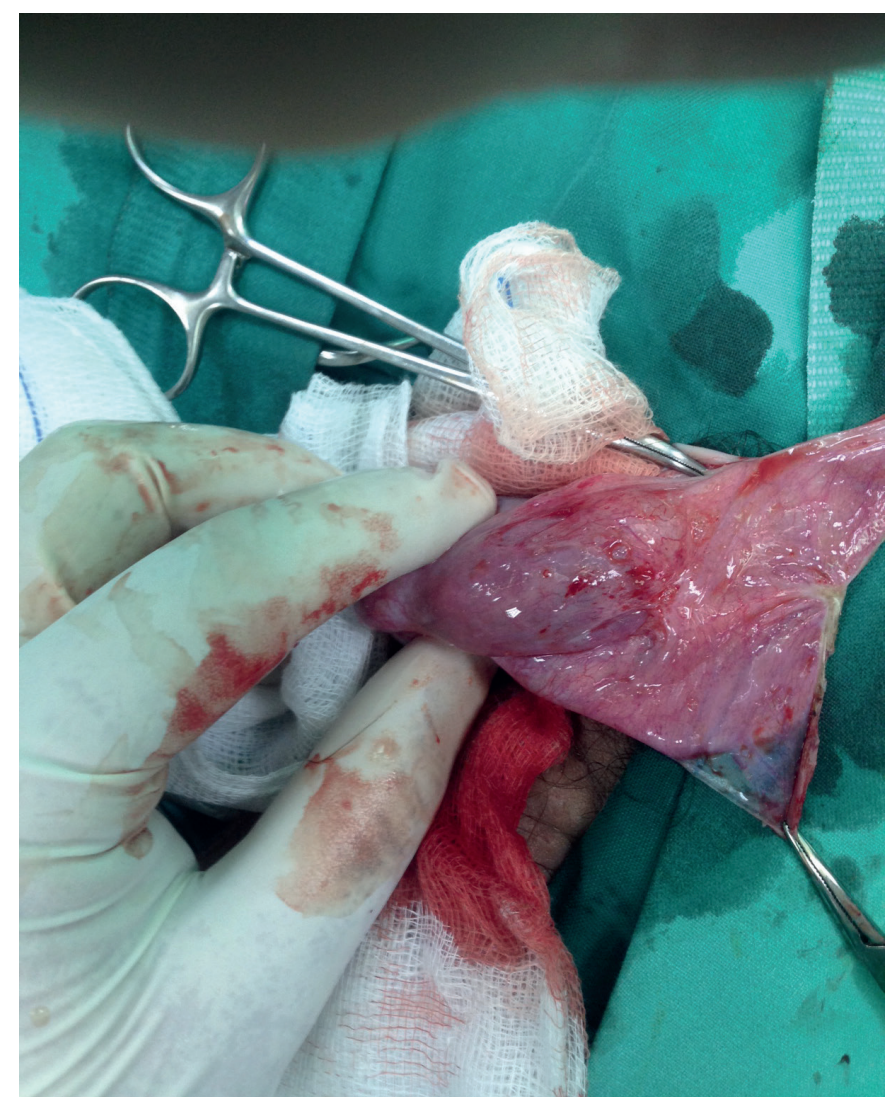

Fig. 3 Notice the punctuated and scattered longitudinal hemorrhagic infiltration as well as thickening of the parietal layer of tunica vaginalis (4th patient).

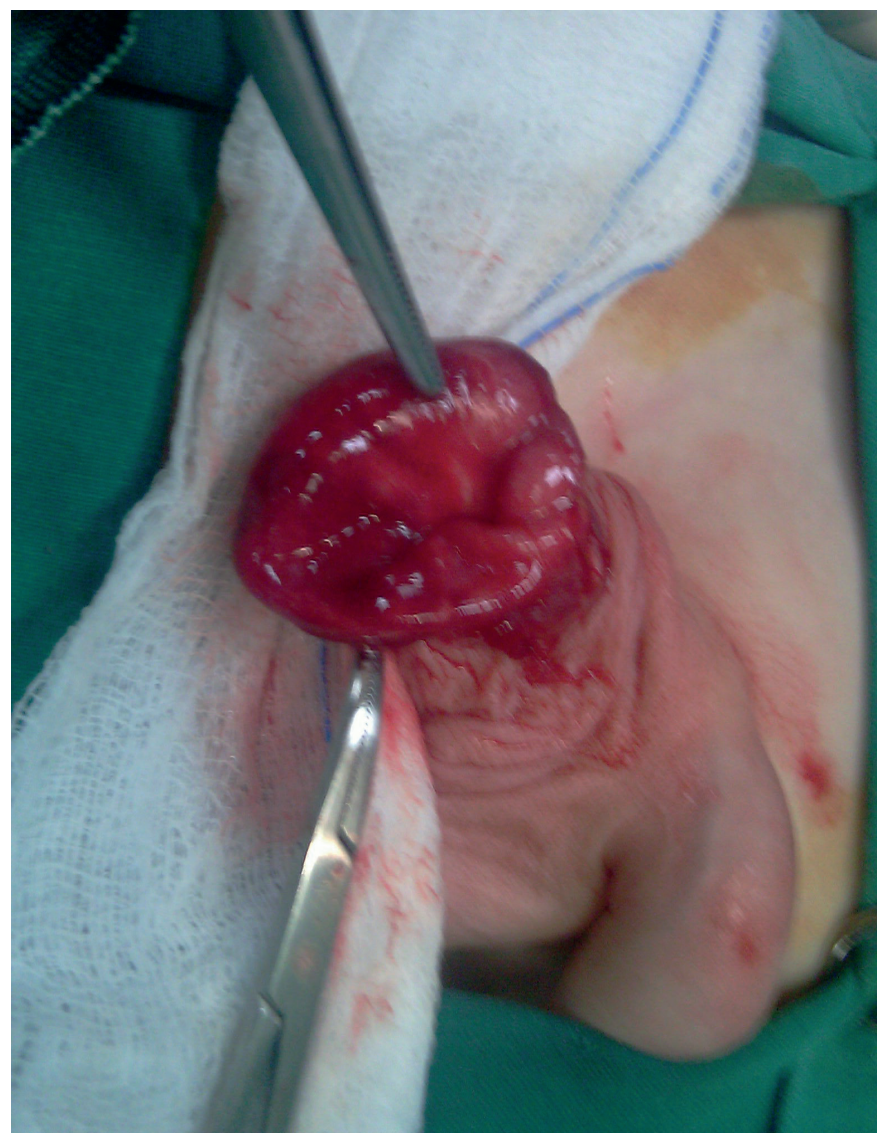

Fig. 4 Sixth patient of our study group. PLTV hemorrhagic infiltration. 
Tab. 3 Analysis of 8 cases of primary hydrocele with hemorrhagic infiltration of parietal tunica vaginalis.

\begin{tabular}{|c|c|c|c|c|c|c|c|}
\hline$S / \mathbf{n}$ & Age (years) & Position & Approach & PPV & Surgical procedure & Recurrence & Treatment \\
\hline 1 & 2.5 & Right & Inguinal & Yes & $\begin{array}{l}\text { high ligation of the processus } \\
\text { vaginalis and reversion of the tunica } \\
\text { vaginalis }\end{array}$ & No & \\
\hline 2 & 4 & Right & Inguinal & Yes & $\begin{array}{l}\text { high ligation of the processus } \\
\text { vaginalis and reversion of the tunica } \\
\text { vaginalis }\end{array}$ & No & \\
\hline 3 & 5 & Left & Inguinal & Yes & $\begin{array}{l}\text { high ligation of the processus } \\
\text { vaginalis and reversion of the tunica } \\
\text { vaginalis }\end{array}$ & No & \\
\hline 4 & 6 & Right & Inguinal & Yes & $\begin{array}{l}\text { high ligation of the processus } \\
\text { vaginalis and reversion of the tunica } \\
\text { vaginalis }\end{array}$ & No & \\
\hline 5 & 7 & Right & Inguinal & Yes & $\begin{array}{l}\text { high ligation of the processus vagina- } \\
\text { lis and sheath fenestration technique }\end{array}$ & Yes & $\begin{array}{l}\text { reversion of the PLTV via scrotal } \\
\text { incision (Jaboulay technique) }\end{array}$ \\
\hline 6 & 10 & Left & Scrotal & No & reversion of the tunica vaginalis & No & \\
\hline 7 & 12 & Right & Scrotal & No & reversion of the tunica vaginalis & No & \\
\hline 8 & 12 & Left & Scrotal & No & reversion of the tunica vaginalis & No & \\
\hline
\end{tabular}

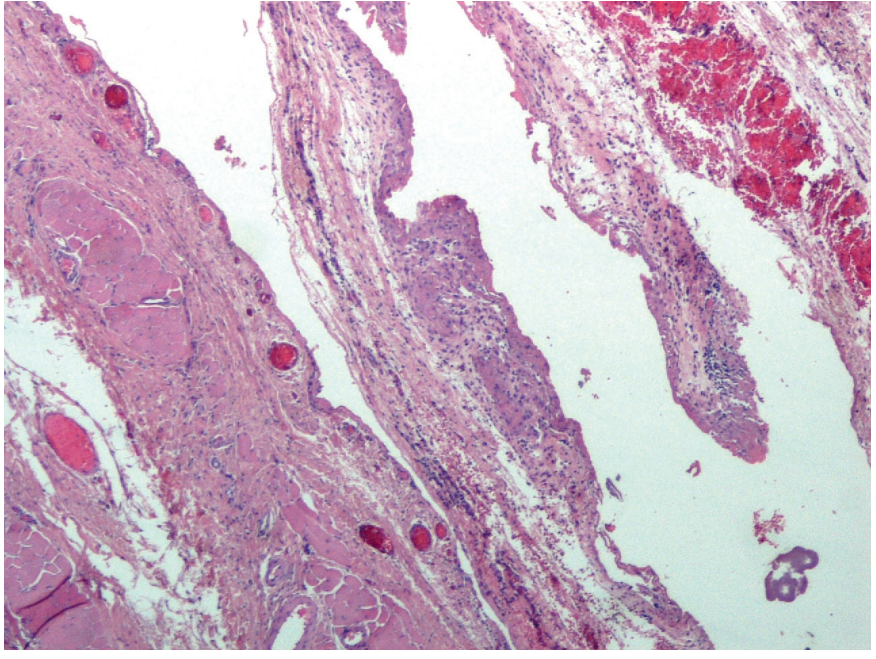

Fig. 5 Fifth patient of our study group: thickening, fibrosis and chronic inflammation of tunica vaginalis.

Cytopathological examination excluded the presence of tumor cells or leukocytes. Histopathological examination of the tissue biopsies of the tunica vaginalis confirmed the presence of thickening - accompanied by intense fibroblastic activity -, absence of mesothelial cells from the inner side of the tunica vaginalis, hemorrhagic infiltration and inflammatory cells (figures 5, 6). Then immunohistochemical examination for desmin was found to be positive.

During a 2-year post-operative follow-up, on a 3-month basis, none of our patients had any recurrence. Ultrasonography was performed in all patients one year after the surgery. No abnormalities in the testicular parenchyma or size were found.

\section{DISCUSSION}

Pediatric surgeon should emphasize on the subject etiology when treating a boy with secondary hydrocele (3). In this

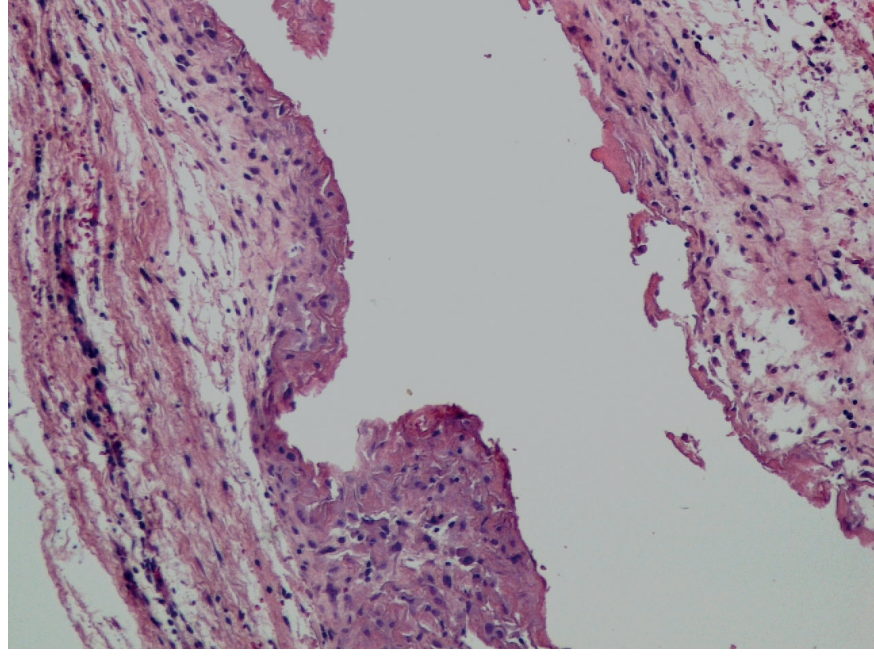

Fig. 6 Fifth patient of our study group: absence of mesothelial cells from the inner side of the tunica vaginalis, while dense fibrosis and infiltration by inflammatory cells are present.

prospective clinical study, cases of secondary hydrocele were excluded. During preoperative approach of a pediatric patient with hydrocele, the surgeon might come across various unusual findings, which may require a more thorough evaluation of the appropriate surgical procedure.

Prior to elective surgery, not only does clinical examination play an important role (thorough medical history and physical examination), but imaging modalities as well (scrotal and inguinal ultrasonography), which can add essential information regarding secondary hydrocele. When talking about secondary hydrocele, the clinician should mainly focus on: parasitic infections (filariasis, shistosomiasis), tuberculosis, syphilis, brucellosis, parotitis, autoimmune diseases (Ehlers Danlos Syndrome), nephrotic syndrome, chronic kidney disease, previous scrotal trauma, inflammatory intrascrotal structures, previous surgery, serositis due to systemic inflammatory response, testicular or paratesticular mass, and hydrocephalus in the presence of a ventriculoperitoneal shunt $(4,5)$. 
None of our patients faced significant changes in size, which is indicative of malignancy, such as malignant mesothelioma of the tunica vaginalis or paratesticular rhabdomyosarcoma $(5,6)$.

Hydrocele repair should always be made on an elective basis and not urgently, in order the complete diagnostic approach to be made and the cases of secondary hydrocele to be excluded.

During physical examination, we assessed the position, the turgidity and the size of the testicles, the silk-glove (or string) sign, the presence of tenderness or pain during palpation and the presence of palpable nodules on the scrotal wall or intrascrotal structures. Transillumination was also conducted as an additional diagnostic method. As inguinoscrotal hernia along with the presence of intestinal loop cannot be excluded, positive transillumination should always be interpreted along with the rest objective clinical findings (3). In contrast, as found in 5 patients of our study group, negative transillumination could be evaluated as related with the thickening of the visceral tunica vaginalis intraoperatively (7).

Ultrasonographic depiction of the thickening of the tunica vaginalis was not feasible in any of our patients. Contrast Enhanced Sonography (CEUS) after bolus intravenous injection of contrast media, which is the most appropriate imaging modality, was not available in our Department (8). Depiction of tunica vaginalis thickening via high-resolution ultrasonography could contribute to preoperative diagnosis. Further appropriate clinical studies are required, in order to investigate and establish its use in clinical practice.

No nodules -solid or mottled and calcified- were seen within the thickened visceral tunica vaginalis, a finding indicative of a reactive fibro-inflammatory reaction. Ultrasonography did not reveal the presence of a single nodule or multinodular thickening of the tunica vaginalis (9). Nonetheless, the pathogenesis of this reaction still remains obscure. It is usually associated with history of prior trauma, Schistosoma Haematobium infection and HIV infection $(10,11,12)$. In case of Schistosoma Haematobium infection, apart from the thickening of visceral tunica vaginalis, ultrasonography would also depict the presence of septa within the tunica vaginalis cavity (multicystic hydrocele) and scattered echoes, as well (9).Ultrasonography did not reveal any focal linear calcification in the inner surface of the tunica vaginalis that would be indicative of diffuse fibrous pseudotumor or fibromatous periorchitis (13).

The "classic" therapy of communicating hydrocele is the closure of the communication between the peritoneal cavity and the cavity defined by the parietal and the visceral layer of tunica vaginalis, by inguinal approach (9). The treatment of choice is the ligation of PPV at the level of the internal inguinal ring, along with incision of the outer layer of the hydrocele sac and creation of a "window" in the parietal tunica vaginalis (sheath fenestration) $(14,15)$.

Cases of abdominoscrotal hydrocele, could be corrected via scrotal approach $(16,17,18)$.

From our study group, recurrence seen in our first patient, who had undergone high ligation of the PPV and "window" creation in the parietal layer of tunica vagina- lis, was an unexpected complication and may be associated with the abnormal function of mesothelial lining. The latter may result either from fluid overproduction or failure of the mesothelial lining to reabsorb the fluid or both. Ozdilek et al. and Rinker et al. consider a non-communicating hydrocele as idiopathic, without associating the subject pathophysiological process with intraoperative findings such as the inflammatory changes of the parietal layer of tunica vaginalis $(19,20)$.

Rinker et al. and Allen suggest that a defective mechanism of lymphatic drainage develops in pediatric patients with hydrocele, finally affecting the drainage of the collected transudate (20). In our study group, collected fluid did not contain lymph in any of our patients.

$\mathrm{Ku}$ et al. consider as inappropriate the creation of a "window" in the parietal layer of tunica vaginalis, as adhesions develop gradually leading finally to "window's" closure. In those cases, recurrence rate of hydrocele reaches up to $85 \%(21)$.

Under this consideration, a more radical surgical intervention such as a partial excision and partial reversion of the tunica vaginalis was implemented. In our study group, reversion without excision of the tunica vaginalis was carried out in 7 patients (Jaboulay operation).

Diagnosis of hydrocele was based upon physical examination and imaging studies in the preoperative period, while biochemical and cytologic examination of hydrocele's fluid and histopathological examination of tissue biopsy taken from the tunica vaginalis completed postoperatively the diagnostic approach. After thorough evaluation of the above, no concomitant pathology was identified in any of our patients.

After evaluating the intraoperative macroscopic features and the histopathologic characteristics and excluding the presence of any concomitance, we made the possible diagnosis of tunica vaginalis mesothelium hyperplasia or reactive mesothelial hyperplasia (22-24). Reactive mesothelial hyperplasia is the most prominent diagnosis. Presence of primary hydrocele, absence of invasive character, absence of participation of the rest scrotal layers in the pathology, absence of lymphocytic infiltration and positive for desmin immunohistochemical reaction constitute the above diagnosis $(22,24-27)$.

There was no indication for further immunohistochemical staining (EMA, p53, GLUT-1, IMP-3) in order to exclude the presence of malignant mesothelioma of the tunica vaginalis. Immunohistochemical staining positive for EMA, p53, GLUT-1, IMP-3 and negative for desmin is indicative of malignant mesothelioma arising from the tunica vaginalis of the testis $(28,29)$. In cases when differential diagnosis is still ambiguous, DNA ploidy can distinguish some borderline lesions (30).

The differential diagnosis between reactive mesothelial hyperplasia and mesothelioma should always be carefully made. Despite the extreme rarity of mesothelioma during childhood, de Lima et al. report a case of a 15-year-old boy with secondary hydrocele and malignant mesothelioma as the etiologic substrate (31).

However, according to the study of Tolhurst et al., no malignancy can be ruled out by the absence of cellular atypia. The authors present a case of concomitance of uni- 
lateral atypical reactive mesothelial hyperplasia and well differentiated mesothelioma contralaterally (32). They therefore consider the presence of invasive behavior as significant parameter, strongly indicative of malignancy. Based upon the histologic examination of the tissue biopsies taken from the parietal layer of the tunica vaginalis, there was no indication of true invasion or prominent infiltration in our study group.

\section{CONCLUSIONS}

1. When inflammatory changes of tunica vaginalis are found as an intraoperative finding in the context of primary hydrocele surgical repair, it is critical to evaluate whether they are secondary or not. Malignant mesothelioma must always be excluded, based upon cytological examination of the fluid and immunohistochemical examination of the tissue biopsy for desmin at initial approach.

2. In communicating hydrocele cases with macroscopic features indicative of inflammation of PTLV, high ligation of the PPV and tunica vaginalis sheath fenestration are accompanied with recurrence. Thus the "classic" operative technique is considered as insufficient. On the contrary, high ligation of PPV along with Jaboulay technique minimizes the recurrence rate.

3. In cases of noncommunicating or adult type hydrocele, scrotal approach and reversion of PLTV lead to the minimization of the recurrence rate.

\section{ACKNOWLEDGEMENTS, FUNDING AND DISCLOSURES}

All the authors contributed equally to the writing of this short review article. None of the contributing authors have any conflict of interest, including specific financial interests or relationships and affiliations relevant to the subject matter or materials discussed in the manuscript.

\section{REFERENCES}

1. Dave J. Cause and management of hydrocele: a review article. Indian J of Applied Research 2015; 5(10): 117-8.

2. DeVries $\mathrm{C}$. The role of urologist in the treatment and elimination of lymphatic filariasis worldwide. BJU Int 2002; 89(1): 37-43.

3. Tahir MS. Hydrocele. Indep Rev 2014; 16(4-6): 145-50.

4. Tarantino L, Giorgio A, de Stefano G, Farella N. Echo color Doppler findings in post pubertal mumps epididymo orchitis. J Ultrasound Med 2001; 20: 1189-95.

5. Zaslau S, Perlmutter AE, Farivar-Mohseni H, Chang WW, Kandzari SJ. Rhabdomyosarcoma of tunica vaginalis masquerading as hydrocele. Urol 2005; 65: 1001.

6. Cimador M, Castagnetti M, De Grazia E. Management of hydrocele in adolescent patients. Nat Rev Urol 2010; 7(7): 379-85.

7. Rubenstein A, Dogra VS, Seftel AD, Resnick MI. Benign intrascrotal lesions. J Urol 2004; 171: 1765-72.
8. Puttermans T, Ingabire MI, Jorion JL, Draguet AP. Fibrous pseudotumor of the tunica vaginalis: contrast enhanced sonography with pathologic correlation. JBR-BTR 2014; 97: 259-61.

9. Garriga V, Serrano A, Marin A, et al. US of tunica vaginalis testis: Anatomic relationships and pathologic conditions. Radiographics 2009; 29: 2017-32.

10. Mostophi FK, Price EB. Tumors of the male genital system. In: Atlas of tumor pathology, 2nd series, Fascicle 8, Wasington DC: Armed Forces Institute Pathology, 1973: 151.

11. Parker PM, Pugliese JM, Allen RC. Benign fibrous pseudotumor of tunica vaginalis testis. Urol 2006; 68: 427e17-e19.

12. Navai N, Yap RL, Gupta R, Fraser TG, Gonzalez CM. Inflammatory pseudotumor of the testis: a novel presentation of acute retroviral syndrome. Int J Urol 2005; 12: 424-6.

13. White WM, Hilsenbeck J, Waters WB. Fibromatous periorchitis of testis. Urology 2006; 67(3): 623.e15-6.

14. Holcomb GW, Murhy JP, Ostlie DJ. Ashcraft's Pediatric Surgery. 6th edition. New York: Elsevier Saunders, 2014, Chapter 50, pp 679-88.

15. Andrews EW. The "Bottle Operation" method for the radical cure of hydrocele. Ann Surg 1907; 46: 915-8.

16. Belman AB. Abdominoscrotal hydrocele in infancy: a review and presentation of the scrotal approach for correction. J Urol 2001; 165(1): 225-7.

17. Koutsoumis G, Patoulias I, Kaselas C. Primary new-onset hydroceles presenting in late childhood and pre-adolescent patients resemble the adult type hydrocele pathology. J Pediatr Surg 2014; 49: 1656-8.

18. Wilson JM, Aaronson DS, Schrader R, Baskin LS. Hydrocele in the pediatric patient: inguinal or scrotal approach? J Urol 2008; 180: $1724-8$.

19. Ozdilek S. The pathogenesis of idiopathic hydrocele and a simple operative technique. J Urol 1957; 77: 282-4.

20. Rinker J, Allen L. A lymphatic defect in hydrocele. Am Surg 1951; 17 : 681-6.

21. Ku JH, Kim M, Lee NK, Park YH. The excisional, plication and internal drainage techniques: a comparison of the results for idiopathic hydrocele. BJU Int 2001; 87: 82-4.

22. Algaba F, Mikuz G, Boccon-Gibod L, et al. Psudoneoplastic lesions of the testis and paratesticular structures. Virchows Archiv 200; 451(6): 987-97.

23. Perez-Ordonez B, Srigley JR. Mesothelial lesions of the paratesticular region. Semin Diagn Pathol 2000; 17: 294-306.

24. Colecchia M, Mikuz G, Algaba F. Rare tumors of the testis and mesothelial proliferation in the tunica vaginalis. Tumori 2012; 98: 270-3.

25. Erdogan S, Acikalin A, Zeren H, et al. Well-Differentiated Papillary Mesothelioma of the Tunica Vaginalis: A Case Study and Review of the Literature. Korean J Pathol 2014; 48(3): 225-8.

26. Bolen JW, Hammar SP, McNutt MA. Reactive and neoplastic serosal tissue. A light-microscopic, ultrastructural, and immunocytochemical study. Am J Surg Pathol 1986; 10: 34-47.

27. Tyagi G, Munn CS, Kiser LC, Wetzner SM, Tarabulcy E. Malignant mesothelioma of tunica vaginalis testis. Urol 1989; 34: 102-4.

28. Chen JL, Hsu YH. Malignant mesothelioma of the tunica vaginalis testis: a case report and literature review. Kaohsiung J Med Sci 2009; 25: 77-81.

29. Goel A, Agrawal A, Gupta R, Hari S, Dey AB. Malignant mesothelioma of the tunica vaginalis of the testis without exposure to asbestos. Cases J 2008; 1: 310.

30. Friedman MT, Gentile P, Tarectecan A, Fuchs A. Malignant mesothelioma: immunohistochemistry and DNA ploidy analysis as methods to differentiate mesothelioma from benign reactive mesothelial cell proliferation and adenocarcinoma in pleural and peritoneal effusions. Arch Pathol Lab Med 1996; 120(10): 959-66.

31. De Lima GR, De Oliveira VP, Reis PH, et al. A rare case of malignant hydrocele in a young patient. J Pediatr Urol 2009; 5(3): 243-5.

32. Tolhurst SR, Lotan T, Rapp DE, et al. Well-differentiated papillary mesothelioma occurring in the tunica vaginalis of the testis with contralateral atypical mesothelial hyperplasia. Urol Oncol 2006; 24: $36-9$. 